\title{
Antenatal steroid treatment reduces childhood asthma risk in very low birth weight infants without bronchopulmonary dysplasia
}

\author{
Yi-Li Hung', Wu-Shiun Hsieh², Hung-Chieh Chou², \\ Yao-Hsu Yang ${ }^{2}$, Chien-Yi Chen ${ }^{2}$ and Po-Nien Tsao ${ }^{2, *}$ \\ ${ }^{1}$ Department of Pediatrics, Cathay General Hospital, \\ Taipei, Taiwan \\ ${ }^{2}$ Department of Pediatrics, National Taiwan University \\ Hospital and National Taiwan University College of \\ Medicine, Taipei, Taiwan
}

\section{Introduction}

Advances in neonatal intensive care strategies and technology markedly improved survival rates of very low birth weight (VLBW) [12]. Despite this, bronchopulmonary dysplasia (BPD) remains a major morbidity in such infants [10, $31,32]$. There is also growing concern, and indeed compelling evidence, about the long-term pulmonary consequences for VLBW infants who had BPD [5, 12, 18].

There appears to be a strong link between BPD and later airway hyperresponsiveness in survivors [13]. There is also evidence suggesting that prematurity/low birth weight per se similarly leads to impaired lung development and pulmonary dysfunction $[4,7,15]$. In addition, a number of studies have reported an increased asthma risk in school-aged children who were VLBW infants [23, 24]. In these studies, however, it was not stated whether the VLBW infants were also afflicted with BPD. Therefore, the aim of the present study is to identify the perinatal and environmental risk factors associated with asthma and active wheezing in children who were VLBW infants but did not suffer from BPD.

\section{Materials and methods}

We identified 158 children (aged 2-8 years) who were born preterm between January 1995 and December 2001. All had been previously admitted to our neonatal intensive care unit at $\leq 32$ weeks' gestational age (GA) with a birth weight $<1500$ g. Children with chromosomal or congenital abnormalities, as well as those who suffered BPD after birth, were excluded from the study. In the current study, BPD was defined as the need for supplemental oxygen at a postnatal age of 28 days with typical radiologic changes [2], and respiratory distress syndrome (RDS) was diagnosed by the clinical presentation and changes on chest imaging [19]. Significant patent ductus arteriosus (PDA) included cases which required medical or surgical intervention. A maternal history of clinical chorioamnionitis was defined as one or more of the following: (i) persistent maternal fever $\geq 37.5^{\circ} \mathrm{C}$ on two or more occasions $\geq 1 \mathrm{~h}$ apart, or a single temperature $\geq 38^{\circ} \mathrm{C}$, prior to delivery, (ii) maternal leukocytosis $\geq 20,000 / \mathrm{mL}$, or (iii) foul smelling amniotic fluid [34]. Postnatal sepsis was specified as a positive blood culture with clinical symptoms or signs of infection. All participants were followed-up at our outpatient clinics.

Parents of the enrolled children were invited by mail to answer the International Study of Asthma and Allergies in Childhood (ISAAC) Core Questionnaire Wheezing Module for 6-7 years children (Table 1). Those who did not initially respond were sent a second questionnaire. Children were categorized as having asthma or not on the basis of "Yes" answers to questions 1 and 6. Children with current active wheezing were those who had experienced

\footnotetext{
*Corresponding author:

Dr. Po-Nien Tsao

National Taiwan University Hospital

No. 7, Chung-Shan South Road

Taipei, 100

Taiwan

Tel.: + 886-2-2312-3456 ext. 3214

Fax: + 886-2-2393-4749

E-mail: tsaopn@gmail.com
}

Keywords: Bronchopulmonary dysp
\end{abstract} corticosteroids; prematurity; very low birth weight. 
wheezing or chest whistling in the previous 12 months (i.e., "Yes", answers to questions 1 and 2). Night-time cough was indicated by a "Yes" answer to question 8. Any answer of "Not sure" was regarded as missing data in the statistical analysis.

Subject information pertaining to Apgar score at birth, antenatal steroid treatment (dexamethasone $8 \mathrm{mg}$ q8h for 1 day per course), premature membrane rupture, RDS, chorioamnionitis, gestational diabetes mellitus, preeclampsia, transient tachypnea of the newborn (TTN), retinopathy of prematurity, intraventricular hemorrhage, surfactant therapy, mechanical ventilation duration, $\mathrm{O}_{2}$ utilization, PDA, and sepsis was obtained by medical record review.

For each subject, we also collected information regarding family history of atopy (allergic rhinitis or bronchial asthma in first-degree relatives), passive exposure to tobacco smoke (defined as a family member living with the child who currently smokes indoors), and indoor feeding of cats or dogs.

Basic study subject characteristics (in both the asthma and nonasthma groups) were first described by mean and standard deviation (SD) or median (range) for continuous variables, and numbers for categorical factors. Differences between groups for continuous and categorical variables were assessed by independent $t$ - and $\chi^{2}$-tests. If the number of any category was $<5$, Fisher's exact tests were performed. To assess the determinants of asthma occurrence, univariate analyses by logistic regressions were applied to estimate the relative risk of each variable for the diagnosis of asthma. Separate multivariate analyses were then performed for GA and gender (these factors displayed high co-linearity) with the various significant factors identified by univariate analyses as well as age at assessment and gender. Birth weight and GA were assessed as categorical variables, in tertiles. In tertiles, these two continuous variables were categorized by $33 \%$ percentiles which transformed the small unit to a bigger one, maximized statistical power, and made a test for trend possible to detect a "dose-response relation". Odds ratios (ORs) with $95 \%$ confidence intervals (CIs) were calculated to estimate the relative risk of asthma. All statistical analyses were performed using SPSS 13.0 for Windows. The significance level was set as 0.05 .

\section{Results}

There was a $74 \%$ response rate (117 out of the 158 VLBW infants identified) to the questionnaires. GA ranged from 22 to 32 weeks. Just $<50 \%$ of the subjects were male. Those who did not respond to the questionnaires were more likely to suffer from retinopathy of prematurity compared with those who completed the questionnaires. There were no significant differences in other perinatal characteristics including GA, birth weight, birth year, use of antenatal steroids, RDS, PDA and sepsis episodes between the questionnaire responders and non-responders. Of the 117 patients, 80 $(68.4 \%)$ had received antenatal steroids and 63 of them completed at least one course of steroids $24 \mathrm{~h}$ before delivery. Infants who received antenatal steroids had a significantly lower incidence of severe RDS with surfactant therapy than infants without antenatal steroids treatment (4/80 vs. 9/37, $\mathrm{P}=0.004)$. In our hospital, excluding uncontrolled premature labor, all VLBW newborns were born by elective cesarean section due to safety considerations. Therefore, 93 out of the 117 enrolled infants $(79.5 \%)$ were born by cesarean section. A total of 22 premature infants had TTN, but infants born by cesarean section did not have a significantly higher risk

Table 1 International study of asthma and allergies in childhood core questionnaire wheezing module for 6-7 years children.

\begin{tabular}{|c|c|c|}
\hline No. & Question & Responses \\
\hline 1 & $\begin{array}{l}\text { Has your child ever had wheezing or whistling in the chest at } \\
\text { any time in the past? }\end{array}$ & $\begin{array}{l}\text { Yes } \\
\text { No (skip to question 6) } \\
\text { Not sure }\end{array}$ \\
\hline 2 & Has your child had wheezing or whistling in the chest in the last 12 months? & $\begin{array}{l}\text { Yes } \\
\text { No (skip to question 6) } \\
\text { Not sure }\end{array}$ \\
\hline 3 & How many attacks of wheezing has your child had in the last 12 months? & $\begin{array}{l}\text { None } \\
1-3 \text { months } \\
4-12 \text { months } \\
>12 \text { months }\end{array}$ \\
\hline 4 & $\begin{array}{l}\text { In the last } 12 \text { months, how often, on average, has your child's sleep been disturbed } \\
\text { because of wheezing? }\end{array}$ & $\begin{array}{l}\text { Never } \\
<1 \text { night per week } \\
\geq 1 \text { nights per week }\end{array}$ \\
\hline 5 & $\begin{array}{l}\text { In the last } 12 \text { months, has wheezing ever been severe enough to } \\
\text { disturb your child's speech? }\end{array}$ & $\begin{array}{l}\text { Yes } \\
\text { No } \\
\text { Not sure }\end{array}$ \\
\hline 6 & Has your child ever had asthma? & $\begin{array}{l}\text { Yes } \\
\text { No } \\
\text { Not sure }\end{array}$ \\
\hline 7 & In the last 12 months, has your child's chest sounded "wheezy" during or after exercise? & $\begin{array}{l}\text { Yes } \\
\text { No } \\
\text { Not sure }\end{array}$ \\
\hline 8 & $\begin{array}{l}\text { In the last } 12 \text { months, has your child had a dry cough at night, apart from a cough } \\
\text { associated with a cold or a chest infection? }\end{array}$ & $\begin{array}{l}\text { Yes } \\
\text { No } \\
\text { Not sure }\end{array}$ \\
\hline
\end{tabular}


Table 2 Basic comparisons in children with and without asthma who were very low birth weight infants $(\mathrm{n}=117)$.

\begin{tabular}{|c|c|c|c|}
\hline Variables & Asthma $(n=22)$ & No asthma $(\mathrm{n}=95)$ & P-value ${ }^{a}$ \\
\hline Age at assessment (months) & 66.5 (24-99) & $55.0(24-107)$ & 0.21 \\
\hline \multicolumn{4}{|l|}{ Gender } \\
\hline Male & 11 & 46 & \multirow[t]{2}{*}{0.89} \\
\hline Female & 11 & 49 & \\
\hline \multicolumn{4}{|l|}{ GA } \\
\hline $1^{\text {st }}$ tertile & 6 & 36 & \multirow[t]{3}{*}{0.61} \\
\hline $2^{\text {nd }}$ tertile & 11 & 43 & \\
\hline $3^{\text {rd }}$ tertile & 5 & 16 & \\
\hline \multicolumn{4}{|l|}{ Body birth weight } \\
\hline $1^{\text {st }}$ tertile & 7 & 32 & \multirow[t]{3}{*}{0.35} \\
\hline $2^{\text {nd }}$ tertile & 5 & 34 & \\
\hline $3^{\text {rd }}$ tertile & 10 & 29 & \\
\hline \multicolumn{4}{|l|}{ Small for gestational age } \\
\hline No & 15 & 65 & \multirow[t]{2}{*}{1.00} \\
\hline Yes & 7 & 30 & \\
\hline Total admission duration (days) & $45.5(25-75)$ & $50.0(22-114)$ & $<0.05^{\mathrm{c}}$ \\
\hline \multicolumn{4}{|l|}{5 min Apgar score $<7^{b}$} \\
\hline No & 21 & 80 & \multirow[t]{2}{*}{0.30} \\
\hline Yes & 1 & 14 & \\
\hline \multicolumn{4}{|l|}{ Premature rupture of membrane } \\
\hline No & 14 & 62 & \multirow[t]{2}{*}{1.00} \\
\hline Yes & 8 & 33 & \\
\hline \multicolumn{4}{|l|}{ Antenatal steroid treatment } \\
\hline No & 11 & 26 & \multirow[t]{2}{*}{$<0.05^{\mathrm{c}}$} \\
\hline Yes & 11 & 69 & \\
\hline \multicolumn{4}{|l|}{ Transient tachypnea of the newborn } \\
\hline No & 16 & 79 & \multirow[t]{2}{*}{0.36} \\
\hline Yes & 6 & 16 & \\
\hline \multicolumn{4}{|l|}{ Respiratory distress syndrome } \\
\hline No & 17 & 74 & \multirow[t]{2}{*}{1.00} \\
\hline Yes & 5 & 21 & \\
\hline Surfactant therapy ${ }^{\mathrm{b}}$ & & & \\
\hline No & 19 & 84 & 0.71 \\
\hline Yes & 3 & 10 & \\
\hline Mechanical ventilation (days) & $0(0-10)$ & $0(0-18)$ & 0.80 \\
\hline Utilization of $\mathrm{O}_{2}>40 \%$ (days) & $0(0-2)$ & $0(0-6)$ & 0.80 \\
\hline Total utilization of $\mathrm{O}_{2}$ (days) & $1(0-44)$ & $3(0-71)$ & 0.86 \\
\hline Significant patent ductus arterios & & & \\
\hline No & 18 & 76 & 1.00 \\
\hline Yes & 4 & 19 & \\
\hline Sepsis during hospitalization ${ }^{\mathrm{b}}$ & & & \\
\hline No & 19 & 77 & 1.00 \\
\hline Yes & 3 & 16 & \\
\hline History of acute bronchiolitis ${ }^{b}$ & & & \\
\hline No & 13 & 79 & $<0.05^{\mathrm{c}}$ \\
\hline Yes & 9 & 16 & \\
\hline Night cough & & & \\
\hline No & 11 & 79 & $<0.01^{\mathrm{c}}$ \\
\hline Yes & 10 & 13 & \\
\hline Family history of atopy & & & \\
\hline No & 6 & 47 & $<0.05^{\mathrm{c}}$ \\
\hline Yes & 14 & 35 & \\
\hline Smoking in family members & & & \\
\hline No & 13 & 66 & 0.32 \\
\hline Yes & 9 & 28 & \\
\hline Pet adopted ${ }^{\mathrm{b}}$ & & & \\
\hline No & 22 & 83 & 0.12 \\
\hline Yes & 0 & 12 & \\
\hline
\end{tabular}

Continuous variables are presented as median (range). Categorical variables are presented numerically.

${ }^{a}$ Independent $t$-tests and $\chi^{2}$-tests were performed for continuous and categorical variables.

${ }^{b}$ Fisher's exact tests were performed.

${ }^{\mathrm{c}}$ Indicates a statistically significant difference between groups $(\mathrm{P}<0.05)$. 
of developing TTN compared with infants born by NSD (20.4\% vs. $12.5 \% \mathrm{P}=0.559)$.

Twenty-two of the children (18.8\%) had asthma. Twentyfive of the children $(21.4 \%)$ had 31 hospitalizations for acute bronchiolitis before age 2 years including 8 episodes of RSV.

Table 2 presents descriptive statistics for the study subjects grouped according to whether or not they suffered from asthma. The following variables were statistically different between the groups: total admission duration, antenatal steroid treatment, history of acute bronchiolitis, night cough, and a family history of atopy. There were no statistically significant differences detected regarding GA or birth weight. In an attempt to increase statistical power, tertiles (i.e., $33 \%$ percentiles) were calculated and compared for these two continuous variables, however, there were still no significant differences (Table 2). There were insufficient cases for analysis of gestational diabetes mellitus, maternal preeclampsia, clinical chorioamnionitis, retinopathy of prematurity and intraventricular hemorrhage in each group.

The univariate analysis is presented in Table 3. There was an increased risk of asthma detected for history of acute bronchiolitis, night cough, family history of atopy and antenatal steroid treatment. As acute bronchiolitis and night cough are asthma-related symptoms, rather than underlying causes per se, they were not included as factors for the multivariate analyses.

As already noted, birth weight and gestation age at birth were considered confounding factors and not included together for multivariate analyses. Findings from the multivariate analysis including GA and the other factors of interest are presented in Table 4. Antenatal steroid treatment and family history of atopy remained significant risk factors. With regards to the multivariate analysis incorporating birth weight (Table 5), antenatal steroid exposure and family history of atopy were also found to be significant.

\section{Discussion}

While previous studies identified BPD and VLBW to be significant risk factors for the development of later pulmonary dysfunction and asthma, no studies to date have solely assessed asthma risk factors in VLBW children who did not suffer from BPD. In this study, we examined a cohort of VLBW infants unaffected by BPD. We found that a family history of atopy was a positive risk factor, and maternal antenatal steroid treatment a negative risk factor for later development of asthma.

Asthma has become a leading cause of morbidity among children over the past 20 years [33]. In southern Taiwan, the prevalence of childhood asthma rose by $\sim 30 \%$ from 1993 to 1997 [33]. Although the diagnosis of childhood asthma lacks a standard criterion, the ISAAC Core Questionnaire can provide useful, valid, and comparable data about the prevalence of asthma in children [27]. Using the ISAAC core questionnaire, we found the incidence of asthma to be $\sim 19 \%$ in our VLBW population. This is in comparison to the worldwide incidence of $10 \%$ [36], and in Taiwan, 7\% [21]. This is significantly less than the rate reported by $\mathrm{Ng}$ et al. in VLBW children (44\%) [25], but is comparable to that noted by Palta and colleagues (19\%) in VLBW children [26]. Asthma was diagnosed using the ISAAC questionnaire in both of these studies, and the children were of similar age to those in our investigation (somewhat older in the Palta et al. study). Although $\mathrm{Ng}$ et al. did not present information regarding BPD [25], presumably a high percentage of the studied VLBW subjects were afflicted, thus explaining the very high overall asthma incidence.

Respiratory morbidity, especially childhood asthma after premature delivery, has a multifactorial etiology [17]. Airway hyperresponsiveness and airway obstruction are consistently found in children born prematurely, even in those without neonatal pulmonary diseases, such as RDS or BPD [7, 8, 20, 30]. Whether this increased responsiveness is due to secondary neonatal lung injury or anatomically small airways is still unclear [7, 27]. A number of previous studies have suggested that there is an inverse relationship between GA and childhood asthma risk. For instance, Bernsen and colleagues determined that asthma risk was inversely related to GA at birth in 6-year-old children [3]. Gessner and Chimonas also found that preterm birth was predictive of later asthma occurrence in children $<10$ years of age [16]. Contrary to these studies, infants at the lower end of the GA spectrum were no worse off than those at the higher end in terms of asthma risk in our cohort of VLBW subjects. This suggests that there might be a cut-off point for GA, where further decreases do not result in a higher risk for asthma.

Other studies have suggested that birth weight per se rather than GA is an important risk factor for later airway hyperresponsiveness and asthma [20,30]. Agosti and colleagues found that asthma risk increased with decreasing birth weight in VLBW infants [1]. However, the subjects were not differentiated with respect to being afflicted with BPD. We did not find that birth weight within our VLBW population was predictive of childhood asthma. If indeed there is an effect of birth weight on asthma susceptibility, our findings suggest that within the VLBW categorization there is little variation.

Our study found that preterm infants with TTN did not have a higher risk of developing childhood asthma. Contrary to our findings, Birnkrant et al. found that TTN was independently associated with childhood asthma, and they hypothesized that TTN may be a marker of deficient pulmonary function reflecting inherited susceptibility to asthma [6]. A possible explanation for our difference is that our enrolled candidates were all extremely premature infants with immature pulmonary structure and function. It is difficult to distinguish TTN from mild RDS. In addition, our case numbers were limited and a very small proportion of infants were born vaginally. More studies are needed to establish whether TTN in extremely preterm neonates relates to subsequent childhood asthma.

A family history of atopy exerts antenatal effects on the fetal immune system, causing a shift to responses biased toward those of T helper 2 cells [11]. A parental (especially maternal) history of allergy and asthma is widely accepted 
Table 3 Risk factors for asthma in children who were very low birth weight infants as determined by univariate analyses $(\mathrm{n}=117$ ).

\begin{tabular}{|c|c|c|c|}
\hline Variables & OR & $95 \% \mathrm{CI}$ & P-value \\
\hline Age at assessment (months) & 1.01 & $0.99,1.03$ & 0.24 \\
\hline \multicolumn{4}{|l|}{ Gender } \\
\hline Male & Ref & - & \multirow[t]{2}{*}{0.89} \\
\hline Female & 0.94 & $0.37,2.37$ & \\
\hline \multicolumn{4}{|l|}{ Gestational age ${ }^{a}$} \\
\hline $1^{\text {st }}$ tertile & Ref & - & \\
\hline $2^{\text {nd }}$ tertile & 1.54 & $0.52,4.56$ & 0.44 \\
\hline $3^{\text {rd }}$ tertile & 1.88 & $0.50,7.06$ & 0.35 \\
\hline \multicolumn{4}{|l|}{ Body birth weight ${ }^{\mathrm{b}}$} \\
\hline $1^{\text {st }}$ tertile & Ref & - & \\
\hline $2^{\text {nd }}$ tertile & 0.67 & $0.19,2.34$ & 0.53 \\
\hline $3^{\text {rd }}$ tertile & 1.58 & $0.53,4.68$ & 0.41 \\
\hline \multicolumn{4}{|l|}{ Small for gestational age } \\
\hline No & Ref & - & \\
\hline Yes & 1.01 & $0.37,2.74$ & 0.98 \\
\hline Total admission duration (days) & 0.98 & $0.95,1.01$ & 0.11 \\
\hline \multicolumn{4}{|l|}{5 min Apgar score $<7$} \\
\hline No & Ref & - & \\
\hline Yes & 0.27 & $0.03,2.19$ & 0.22 \\
\hline \multicolumn{4}{|l|}{ Premature rupture of membrane } \\
\hline No & Ref & - & \\
\hline Yes & 1.07 & $0.41,2.82$ & 0.89 \\
\hline \multicolumn{4}{|l|}{ Antenatal steroid treatment } \\
\hline No & Ref & - & \\
\hline Yes & 0.38 & $0.15,0.97$ & $<0.05^{\mathrm{c}}$ \\
\hline \multicolumn{4}{|l|}{ Respiratory distress syndrome } \\
\hline No & Ref & - & \\
\hline Yes & 1.04 & $0.34,3.14$ & 0.95 \\
\hline \multicolumn{4}{|l|}{ Surfactant therapy } \\
\hline No & Ref & - & \\
\hline Yes & 1.33 & $0.33,5.29$ & 0.69 \\
\hline Mechanical ventilation (days) & 0.99 & $0.87,1.11$ & 0.82 \\
\hline Utilization of $\mathrm{O}_{2} 40 \%$ (days) & 0.94 & $0.54,1.65$ & 0.84 \\
\hline Total utilization of $\mathrm{O}_{2}$ (days) & 1.00 & $0.96,1.04$ & 0.86 \\
\hline \multicolumn{4}{|l|}{ Significant patent ductus arteriosus } \\
\hline No & Ref & - & \\
\hline Yes & 0.89 & $0.27,2.94$ & 0.85 \\
\hline \multicolumn{4}{|l|}{ Sepsis during hospitalization } \\
\hline No & Ref & - & \\
\hline Yes & 0.76 & $0.20,2.88$ & 0.69 \\
\hline \multicolumn{4}{|l|}{ History of acute bronchiolitis } \\
\hline No & Ref & - & \\
\hline Yes & 3.42 & $1.25,9.34$ & $<0.05^{\mathrm{c}}$ \\
\hline \multicolumn{4}{|l|}{ Night cough } \\
\hline No & Ref & - & \\
\hline Yes & 5.52 & $1.96,15.60$ & $<0.01^{\mathrm{c}}$ \\
\hline \multicolumn{4}{|l|}{ Family history of atopy } \\
\hline No & Ref & - & \\
\hline Yes & 3.13 & $1.10,8.97$ & $<0.05^{\mathrm{c}}$ \\
\hline \multicolumn{4}{|l|}{ Smoking in family members } \\
\hline No & Ref & - & \\
\hline Yes & 1.63 & $0.63,4.25$ & 0.33 \\
\hline
\end{tabular}

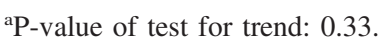

${ }^{\mathrm{b}} \mathrm{P}$-value of test for trend: 0.39 .

'Indicates a statistically significant risk factor.

$\mathrm{OR}=$ odds ratio, $\mathrm{CI}=$ confidence interval. 
Table 4 Risk factor multivariate analysis (excluding birth weight) for asthma in children who were very low birth weight infants ( $\mathrm{n}=117$ ).

\begin{tabular}{|c|c|c|c|}
\hline Variables & OR & $95 \% \mathrm{CI}$ & P-value \\
\hline \multicolumn{4}{|l|}{ Gestational age $^{\mathrm{a}}$} \\
\hline $1^{\text {st }}$ tertile & Ref & - & \\
\hline $2^{\text {nd }}$ tertile & 1.70 & $0.49,5.94$ & 0.41 \\
\hline $3^{\text {rd }}$ tertile & 1.97 & $0.44,8.85$ & 0.38 \\
\hline Age at assessment (months) & 1.01 & $0.99,1.04$ & 0.35 \\
\hline \multicolumn{4}{|l|}{ Gender } \\
\hline Male & Ref & - & \\
\hline Female & 0.70 & $0.24,2.06$ & 0.52 \\
\hline \multicolumn{4}{|l|}{ Antenatal steroid treatment } \\
\hline No & Ref & - & \\
\hline Yes & 0.27 & $0.08,0.88$ & $<0.05^{\mathrm{b}}$ \\
\hline \multicolumn{4}{|l|}{ Family history of atopy } \\
\hline No & Ref & - & \\
\hline Yes & 4.90 & $1.50,15.96$ & $<0.01^{\mathrm{b}}$ \\
\hline
\end{tabular}

a-value of test for trend: 0.35 .

bindicates a statistically significant risk factor.

$\mathrm{OR}=$ odds ratio, $\mathrm{CI}=$ confidence interval .

Table 5 Risk factor multivariate analysis (excluding gestational age) for asthma in children who were very low birth weight infants $(\mathrm{n}=117)$.

\begin{tabular}{|c|c|c|c|}
\hline Variables & OR & $95 \% \mathrm{CI}$ & P-value \\
\hline \multicolumn{4}{|l|}{ Body birth weight ${ }^{a}$} \\
\hline $1^{\text {st }}$ tertile & Ref & - & \\
\hline $2^{\text {nd }}$ tertile & 0.65 & $0.15,2.74$ & 0.56 \\
\hline $3^{\text {rd }}$ tertile & 1.65 & $0.47,5.82$ & 0.44 \\
\hline Age at assessment (months) & 1.01 & $0.99,1.03$ & 0.48 \\
\hline \multicolumn{4}{|l|}{ Gender } \\
\hline Male & Ref & - & \\
\hline Female & 0.69 & $0.24,2.05$ & 0.51 \\
\hline \multicolumn{4}{|l|}{ Antenatal steroid treatment } \\
\hline No & Ref & - & \\
\hline Yes & 0.23 & $0.06,0.79$ & $<0.05^{\mathrm{b}}$ \\
\hline \multicolumn{4}{|l|}{ Family history of atopy } \\
\hline No & Ref & - & \\
\hline Yes & 4.76 & $1.44,15.68$ & $<0.05^{\mathrm{b}}$ \\
\hline
\end{tabular}

${ }^{\text {aP }}$-value of test for trend: 0.42 .

${ }^{\mathrm{b}}$ Indicates a statistically significant risk factor.

$\mathrm{OR}=$ odds ratio, $\mathrm{CI}=$ confidence interval.

as a risk factor for persistent sensitization and childhood asthma $[11,35]$. In a previous population-based study in southern Taiwan, a family history of atopy was obviously associated with childhood asthma $(\mathrm{OR}=3.237)$ [33]. Bertrand et al. [4] and Evans et al. [14] had similar findings, as have Palta et al. [26] in a study of VLBW children. In keeping with these findings, we noted a strong association between familial atopy and asthma risk in our population of VLBW subjects.

An unexpected finding in our study was that antenatal maternal steroid therapy was an independent protective factor against childhood asthma in children who were VLBW infants. Such a finding has not been previously reported. Contrary to our findings, Grischkan et al. found that there was an increased risk for asthma in 8-11-year-old children who were born preterm ( $\leq 36$ weeks) and treated with post- natal steroids [17], whereas Palta et al. reported a borderline significant protective effect of antenatal steroid treatment on wheezing in 8-year-old VLBW children [26]. Dalziel et al. found that antenatal exposure to a single course of betamethasone dose not alter prevalence of wheezes and asthma at age 30 years, but only $14 \%$ of their participants were born at $<1500 \mathrm{~g}$ [9]. From these findings (including ours) it would appear that antenatal and postnatal steroid treatment might have differing effects on asthma risk. A likely explanation for our finding is that antenatal steroid therapy may have enhanced lung maturation and therefore minimized secondary pulmonary injury caused by mechanical ventilation and supplemental oxygen. Indeed, antenatal steroids are well known to reduce the occurrence of $\operatorname{RDS}[22,28,29]$. Additional studies in different populations are warranted to further explore the impact of steroid treatment on asthma prevalence. 
There is some limitation to our study. Because asthma may be difficult to identify in children with previous BPD, our study excluded infants with BPD and we required both a doctor's diagnosis and current wheezes to be classified as asthmatic. However, because analyses were based on children born prematurely with a wide range of ages (from 2 to 8 years) at assessment, we cannot determine whether or not these perinatal effects on asthma are primarily mediated through increased susceptibility to lower respiratory tract infections during infancy. Further investigations should be done to differentiate infection related wheeze from atopic wheeze in these children.

In summary, we have presented an analysis of the risk factors for childhood asthma in VLBW children without BPD. We demonstrated that maternal antenatal steroid treatment was associated with a protective effect in terms of asthma occurrence whereas a familial history of atopy was predictive for childhood asthma in our cohort. The finding regarding the protective effect of antenatal steroids warrants further investigation in other populations, including those who suffered BPD after birth.

\section{References}

[1] Agosti M, Vegni C, Gangi S, Benedetti V, Marini A. Allergic manifestations in very low birth weight infants: a 6-year follow-up. Acta Paediatr Suppl. 2003;91:44-7.

[2] Bancalari E, Abdenour GE, Feller R, Gannon J. Bronchopulmonary dysplasia: clinical presentation. J Pediatr. 1979; 95:819-23.

[3] Bernsen RM, de Jongste JC, Koes BW, Aardoom HA, van der Wouden JC. Perinatal characteristics and obstetric complications as risk factors for asthma, allergy and eczema at the age of 6 years. Clin Exp Allergy. 2005;35:1135-40.

[4] Bertrand JM, Riley SP, Popkin J, Coates AL. The long-term pulmonary sequelae of prematurity: the role of familial airway hyperreactivity and the respiratory distress syndrome. $\mathrm{N}$ Engl J Med. 1985;312:742-5.

[5] Bhutani VK, Abbasi S. Long-term pulmonary consequences in survivors with bronchopulmonary dysplasia. Clin Perinatol. 1992;19:649-71.

[6] Birnkrant DJ, Picone C, Markowitz W, Khwad ME, Shen WH, Tafari N. Association of transient tachypnea of the newborn and childhood asthma. Pediatr Pulmonol. 2006;41: 978-84.

[7] Chan KN, Noble-Jamieson CM, Elliman A, Bryan EM, Aber VR, Silverman M. Airway responsiveness in low birth weight children and their mothers. Arch Dis Child. 1988;63:905-10.

[8] Coates AL. Chronic lung disease in infants - long-term pulmonary sequelae. Pediatr Pulmonol Suppl. 1997;16:40-2.

[9] Dalziel SR, Rea HH, Walker NK, Parag V, Mantel C, Rodgers A, et al. Long term effects of antenatal betamethasone on lung function: 30 year follow up of a randomized controlled trial. Thorax. 2006;61:678-83.

[10] Darlow BA, Cust AE, Donoghue DA. Improved outcomes for very low birthweight infants: evidence from New Zealand national population based data. Arch Dis Child Fetal Neonatal Ed. 2003;88:F23-8.
[11] Devereux G, Barker RN, Seaton A. Antenatal determinants of neonatal immune responses to allergens. Clin Exp Allergy. 2002;32:43-50.

[12] Doyle LW, Faber B, Callanan C, Freezer N, Ford GW, Davis NM. Bronchopulmonary dysplasia in very low birth weight subjects and lung function in late adolescence. Pediatrics. 2006;118:108-13.

[13] Eber E, Zach MS. Long term sequelae of bronchopulmonary dysplasia (chronic lung disease of infancy). Thorax. 2001; 56:317-23.

[14] Evans M, Palta M, Sadek M, Weinstein MR, Peters ME. Associations between family history of asthma, bronchopulmonary dysplasia, and childhood asthma in very low birth weight children. Am J Epidemiol. 1998;148:460-6.

[15] Galdes-Sebaldt M, Sheller JR, Grogaard J, Stahlman M. Prematurity is associated with abnormal airway function in childhood. Pediatr Pulmonol. 1989;7:259-64.

[16] Gessner BD, Chimonas MA. Asthma is associated with preterm birth but not small for gestational age status among a population-based cohort of Medicaid-enrolled persons $<10$ years of age. Thorax. 2007;62:231-6.

[17] Grischkan J, Storfer-Isser A, Rosen CL, Larkin EK, Kirchner HL, South A, et al. Variation in childhood asthma among former preterm infants. J Pediatr. 2004;144:321-6.

[18] Halvorsen T, Skadberg BT, Eide GE, Roksund OD, Carlsen KH, Bakke P. Pulmonary outcome in adolescents of extreme preterm birth: a regional cohort study. Acta Paediatr. 2004; 93:1294-300.

[19] Hansen T, Corbet A. Disorders of the transition. In: Taeusch H, Ballard R, editors. Avery's diseases of the newborn, 7th ed. Phildelphia: W.B. Saunders Co.; 1998:602-13.

[20] Kennedy JD, Edward LJ, Bates DJ, Martin AJ, Dip SN, Haslam RR, et al. Effects of birth weight and oxygen supplementation on lung function in late childhood in children of very low birth weight. Pediatr Pulmonol. 2000;30:32-40.

[21] Liao MF, Huang JL, Chiang LC, Wang FY, Chen CY. Prevalence of asthma, rhinitis, and eczema from ISAAC survey of schoolchildren in Central Taiwan. J Asthma. 2005;42: $833-7$.

[22] Liggins GC, Howie RN. A controlled trial of antepartum glucocorticoid treatment for prevention of the respiratory distress syndrome in premature infants. Pediatrics. 1972;50:515-25.

[23] McCormick MC, Brooks-Gunn J, Workman-Daniels K, Turner J, Peckham GJ. The health and developmental status of very low-birth-weight children at school age. J Am Med Assoc. 1992;267:2204-8.

[24] McLeod A, Ross P, Mitchell S, Tay D, Hunter L, Hall A, et al. Respiratory health in a total very low birth weight cohort and their classroom controls. Arch Dis Child. 1996;74: 188-94.

[25] Ng DK, Lau WY, Lee SL. Pulmonary sequelae in long-term survivors of bronchopulmonary dysplasia. Pediatr Int. 2000; 42:603-7.

[26] Palta M, Sadek-Badawi M, Sheehy M, Albanese A, Weinstein M, McGuinness G, et al. Respiratory symptoms at age 8 years in a cohort of very low birth weight children. Am J Epidemiol. 2001;154:521-9.

[27] Remes ST, Pekkanen J, Remes K, Salonen RO, Korppi M. In search of childhood asthma: questionnaire, tests of bronchial hyperresponsiveness, and clinical evaluation. Thorax. 2002;57:120-6.

[28] Schutte MF, Treffers PE, Koppe JG, Breur W. The influence of betamethasone and orciprenaline on the incidence of res- 
piratory distress syndrome in the newborn after preterm labour. Br J Obstet Gynaecol. 1980;87:127-31.

[29] Schutte MF, Treffers PE, Koppe JG. Threatened preterm labor: the influence of time factors on the incidence of respiratory distress syndrome. Obstet Gynecol. 1983;62:287-93.

[30] Seidman DS, Laor A, Gale R, Stevenson DK, Danon YL. Is low birth weight a risk factor for asthma during adolescence? Arch Dis Child. 1991;66:584-7.

[31] Tsao PN, Wu TJ, Teng RJ, Tang JR, Yau KI. Comparison of the outcome of extremely-low-birth-weight infants between two periods. Zhonghua Min Guo Xiao Er Ke Yi Xue Hui Za Zhi. 1998;39:233-6.

[32] Tsou KI, Tsao PN. The morbidity and survival of very-lowbirth-weight infants in Taiwan. Acta Paediatr Taiwan. 2003; 44:349-55.

[33] Tsuang HC, Su HJ, Kao FF, Shih HC. Effects of changing risk factors on increasing asthma prevalence in southern Taiwan. Paediatr Perinat Epidemiol. 2003;17:3-9.
[34] von Dadelszen P, Kives S, Delisle MF, Wilson RD, Joy R, Ainsworth $\mathrm{L}$, et al. The association between early mem-frane rupture, latency, clinical chorioamnionitis, neonatal infection and adverse perinatal outcomes in twin pregnancies complicated by preterm prelabour rupture of membranes. Twin Res. 2003;6:257-62.

[35] von Mutius E. Environmental factors influencing the development and progression of pediatric asthma. J Allergy Clin Immunol. 2002;109:S525-32.

[36] Worldwide variations in the prevalence of asthma symptoms: the International Study of Asthma and Allergies in Childhood (ISAAC). Eur Respir J. 1998;12:315-35.

The authors stated that there are no conflicts of interest regarding the publication of this article.

Received November 18, 2008. Revised August 11, 2009. Accepted August 21, 2009. Previously published online November 18, 2009. 